\title{
The Reach of Depression Screening Preceding Treatment: Are There Patterns of Patients' Self-Selection?
}

\author{
Dea Ajduković, ${ }^{1}$ Mirjana Pibernik-Okanović, ${ }^{1}$ Mario Šekerija, ${ }^{2}$ and Norbert Hermanns ${ }^{3}$ \\ ${ }^{1}$ Unit for Psychological Medicine, Vuk Vrhovac University Clinic, Merkur Teaching Hospital, Zajčeva 19, 10000 Zagreb, Croatia \\ ${ }^{2}$ Service for the Epidemiology of Non-Communicable Diseases, Croatian National Institute of Public Health, Rockefellerova 7, \\ 10000 Zagreb, Croatia \\ ${ }^{3}$ Forschungsinstitut Diabetes-Akademie Bad Mergentheim (FIDAM GmbH), Diabetes Zentrum Mergentheim, \\ Johann-Hammer-Straße 24, 97980 Bad Mergentheim, Germany
}

Correspondence should be addressed to Mirjana Pibernik-Okanović, pibernik@idb.hr

Received 31 July 2012; Revised 21 September 2012; Accepted 9 October 2012

Academic Editor: Jeffrey S. Gonzalez

Copyright (c) 2012 Dea Ajduković et al. This is an open access article distributed under the Creative Commons Attribution License, which permits unrestricted use, distribution, and reproduction in any medium, provided the original work is properly cited.

\begin{abstract}
This study evaluated the reach of depression screening followed by treatment programs for subsyndromal depression and explored demographic and clinical characteristics of patients who were reached versus those who were not. A two-item Patient Health Questionnaire-Depression was sent to 4196 type 2 diabetic patients. Positively screened patients were interviewed to assess the severity of depression, and those with subclinical symptoms were invited to treatment groups. The reach of screening procedure was evaluated by the total response rate, proportion of positive depression screenings, and proportion of eligible patients entering treatment programs. Predictors of responsiveness to screening and of participation in treatment were determined using logistic regression. Of the $34 \%$ of patients who returned the questionnaire $(n=1442), 40 \%$ reported depressive symptoms and a need for professional help $(n=581)$. Age $(\mathrm{OR}=1.06,95 \% \mathrm{CI}=1.05-1.08)$, $\mathrm{BMI}(\mathrm{OR}=1.02,95 \% \mathrm{CI}=1.00-1.04), \mathrm{HbA} 1 \mathrm{C}(\mathrm{OR}=.92,95 \%$ $\mathrm{CI}=.86-.99)$, and LDL-cholesterol $(\mathrm{OR}=.90,95 \% \mathrm{CI}=.81-1.00)$ correlated with response to screening. Willingness to accept treatment was predicted by professional status $(\mathrm{OR}=3.24,95 \% \mathrm{CI}=1.53-6.87)$, education $(\mathrm{OR}=1.21,95 \% \mathrm{CI}=1.05-1.38)$, and BMI $(\mathrm{OR}=.91,95 \% \mathrm{CI}=.85-.98)$. Older patients with better diabetes control were more likely to be reached by postal screening for depressive symptoms. Professionally inactive, better-educated persons and those with lower BMI were more likely to participate in the intervention for subsyndromal depression.
\end{abstract}

\section{Introduction}

Elevated depressive symptoms are common in diabetic patients, implying impaired quality of life [1] as well as difficulties in self-managing diabetes [2] and achieving desirable metabolic control [3]. Depression increases the risk for diabetic complications and mortality, not only in patients with severe forms of depression but also in those with mild, that is, subclinical, depressive symptoms [4-6].

Despite the clear evidence that the interaction between depression and diabetes is associated with adverse health outcomes, depression remains unrecognized in approximately half of diabetic patients and is consequently not treated properly $[7,8]$. International guidelines currently advocate regular assessment of patients' well-being $[9,10]$ aimed at improving rates of recognition of emotional problems in people suffering from diabetes. These guidelines stress the importance of "incorporating psychological assessment and treatment into routine care rather than waiting for identification of a specific problem or deterioration in psychological status" [9]. The IDF guideline for type 2 diabetes mellitus advises to "assess well being and psychological status periodically, by questioning or validated measures." The relevance of screening questionnaires to improve quality of care for depression has also been supported by the UK National Institute for Health and Clinical Excellence [11].

Many instruments assessing depressive mood have demonstrated sufficient sensitivity and specificity for detecting depressive symptoms in patients with diabetes $[12,13]$. For screening purposes, short instruments focused on core depressive symptoms, such as the PHQ-2 [14], have been shown to be as useful as those containing a greater number 
of items, such as the CES-D or PHQ-9 $[15,16]$. However, screening itself has not been shown to have an impact either on the recognition of depression or on its management and outcomes [17, 18]. In a recent RCT by Pouwer et al. [19], depression screening with written feedback to the patient and physician has not reduced depressive symptoms and has had a limited impact on the use of mental health service in comparison with care as usual. Similar findings were obtained in other patient populations $[18,20]$, suggesting that recommendations to adopt screening strategies are justified only if treatments are planned and provided.

Some studies in the field of diabetes have proven that combining assessment of emotional well-being with subsequent clinical interventions might be more promising in improving mood- and diabetes-related issues. A randomized controlled trial by Pouwer et al. [21] and a longitudinal study by Snoek et al. [22] have demonstrated that computerized assessment of psychological well-being followed by a discussion with a diabetes nurse specialist has improved psychological outcomes. In studies by Katon et al., positive effects of screening on depressive outcomes were observed when screening was embedded in a collaborative care intervention for depression $[23,24]$. It can be concluded that the efficacy of screening depends on its integration into comprehensive treatment approaches including education for behavioral activation and self-management, followup, and, if necessary, referring patients to mental health services in order to intensify treatment.

In spite of the growing consensus on the value of early recognition of depressive symptoms in diabetic patients combined with appropriate interventions, there has been little published research on the reach of screening procedures in a real-world population of type 2 diabetic patients as well as on the proportion of patients who are willing to accept treatment for emotional difficulties. Also, little is known about whether diabetic persons who respond to depression screening and choose to enroll in depression treatment programs differ from those who do not in terms of demographic and disease-related characteristics.

This study was aimed to assess the reach of depression screening followed by treatment programs for subsyndromal depression and to explore demographic and clinical characteristics of patients who were reached versus those who were not. The study was a part of a three-arm randomized controlled trial comparing a six-week psychoeducational or physical exercise course and diabetes reeducation to address subclinical depression.

\section{Materials and Methods}

A cohort of 4196 type 2 diabetes patients was retrieved from a database of diabetic patients [25] based on the criteria of having type 2 diabetes, being between 18 and 65 years old, and having attended at least one diabetes specialist checkup in the previous year. Patients older than 65 years were assumed to be less likely to meet the inclusion criteria for the treatments following the screening procedure, particularly for physical exercise, thus making the recruitment process more complicated. In addition, literature data indicate that elderly diabetic patients with depressive symptoms have specific needs which have to be addressed in an adjusted way [26]. The study was carried out at the Vuk Vrhovac University Clinic, a referral centre for the treatment of diabetes, in Zagreb, Croatia.

The patients were sent a letter explaining the importance of recognizing and treating depression in persons with diabetes and briefly informing them that a free-of-charge behavioral treatment program was available to patients who reported such difficulties [27]. However, specific descriptions of the available programs were not given at this point in the study.

The letter included a yes/no version of the two-item screening instrument for depression, the Patient Health Questionnaire (PHQ-2) [28], and an additional question inquiring into the patients' need to receive help in moodrelated issues [29]. Adding the question about a need for help was shown to increase the specificity of the instrument [30].

The patients were provided with reply-paid envelopes and instructed to return the completed questionnaire regardless of their responses. They were also asked for permission to be contacted by phone if they indicated an interest in receiving help in mood-related issues.

Patients with positive screening results were telephoned to collect sociodemographic and personal data (professional, economic, and family status, and self-reported acute and chronic stress) and to assess the severity of depressive symptoms by administering a structured clinical interview (SCID-I). Persons who met criteria for major depressive disorder or dysthymia, patients with a history of serious psychiatric disorders (psychosis, bipolar affective disorder), and those who were receiving psychiatric treatment were not included in the treatment trial. Instead, they were advised to refer to their GP or psychiatrist, as they required more intensive treatment. Respondents were classified as having subclinical depressive symptoms if they did not meet diagnostic criteria for major depressive disorder or dysthymia. The rationale and the structure of the psychoeducational, physical exercise, and diabetes reeducation treatments were explained to the eligible patients, and they were asked for permission to be randomized to one of the groups. A general agreement to participate was considered the basis for randomization. Its results were presented to the patients at the first appointment, when their written consent was asked for.

Disease-related data including diabetes duration, BMI, HbA1C, total cholesterol, LDL, HDL, triglycerides, and albumin/creatinine ratio were extracted from the electronic files of the entire patient sample $(n=4196)$. Values obtained at the most recent medical checkup within the previous year were used for statistical analyses.

The reach of the screening procedure was evaluated based on the total response rate, the proportion of positive depression screenings, and the proportion of eligible patients who entered the treatment programs. Demographic and diabetes-related differences between patients who responded versus those who did not respond to screening, and between eligible patients who entered the treatment programs versus those who declined to participate were tested using one-way 
ANOVAs, $\chi^{2}$ tests, and multivariate logistic regression analyses, and the effect sizes for comparisons of continuous variables were determined using Cohen's $d$.

\section{Results}

Of the 4196 PHQ-2 questionnaires sent to type 2 diabetic patients who were actively treated at the Vuk Vrhovac University Clinic for Diabetes, 1442 were returned, giving the response rate of $34 \%$. Fifty-three letters were returned by the postal service because the recipient could not be reached, 19 patients denied having type 2 diabetes, and 16 patients were reported to have died.

Of the $34 \%$ of patients who returned the questionnaire ( $n=1442), 40 \%$ reported at least one elevated depressive symptom and a need for professional help $(n=583)$. Approximately one-half of them (57\%, $n=330)$ were considered eligible for treatment, while others were excluded based on the predefined criteria. Out of the eligible patients, 191 entered the treatment programs, 91 declined to do so, and 48 were unreachable after initial contact. Responsiveness to screening, reporting depressive symptoms, and expressing a need for help were comparable between female and male respondents (all $P$ 's $>0.05$ ).

A flow-chart of screening and recruiting patients for the treatment of subsyndromal depression is described in Figure 1.

A comparison between demographic and biochemical data of respondents and nonrespondents is given in Table 1. Univariate analyses revealed that respondents were older $(58.5 \pm 5.65$ versus $55.4 \pm 8.19$ years, $P<.001)$ and had lower $\mathrm{HbA1C}(7.1 \pm 1.32$ versus $7.2 \pm 1.39 \%, P=.031)$ and LDL cholesterol $(2.92 \pm .976$ versus $3.00 \pm 1.046 \mathrm{mmol} / \mathrm{L}$, $P=.014)$ and higher HDL cholesterol (1.34 \pm .327 versus $1.32 \pm .322 \mathrm{mmol} / \mathrm{L}, P=.045)$. In the fully controlled multivariate model, age $(\mathrm{OR}=1.06,95 \% \mathrm{CI}=1.05-1.08)$, BMI $(\mathrm{OR}=1.02,95 \% \mathrm{CI}=1.00-1.04), \mathrm{HbA} 1 \mathrm{C}(\mathrm{OR}=.92$, 95\% CI = 0.86-.99), and LDL cholesterol $(\mathrm{OR}=.90,95 \%$ $\mathrm{CI}=0.81-1.00)$ emerged as correlates of responding to the questionnaire.

Demographic and diabetes-related data characterizing the subgroups of eligible patients who accepted the treatment versus those who did not accept it are given in Table 2. Treated patients differed from the patients who declined treatment at the point of signing consent with respect to BMI and triglycerides-both disease-related indicators were shown to be better in the treatment participants $(P=0.02$ and $P=0.02$, resp.). All other clinical characteristics including HbA1C, cholesterol, LDL, HDL, and albumin/creatinine ratio were comparable across the two groups (all $P$ 's > $0.05)$. The proportion of professionally inactive patients was greater in the group of participating patients, while female gender reached borderline significance $(P=0.07)$. Other demographic variables including education, socioeconomic, and family status, as well as self-evaluations of acute and chronic psychological stress, were not shown to be associated with accepting or declining treatment.

Multivariate logistic regression analysis defining treatment participation as the dependent variable and BMI,
HbA1C, LDL, HDL, triglycerides, gender, age, education, and socioeconomic, family, and professional status as predictors revealed professional inactivity $(\mathrm{OR}=3.24,95 \% \mathrm{CI}=$ 1.53-6.87), higher level of education $(\mathrm{OR}=1.21,95 \% \mathrm{CI}=$ 1.05-1.38), and lower BMI ( $\mathrm{OR}=.91,95 \% \mathrm{CI}=.85-.98)$ to be independent predictors of patients' readiness to be treated for subsyndromal depression.

\section{Discussion}

To the best of our knowledge, this is the first published study that investigated the diabetes-related characteristics associated with (non)responding to depression screening and willingness to participate in behavioral treatment of subsyndromal depression. A postal screening for depressive symptoms gave a $34 \%$ response rate, with $40 \%$ of the respondents reporting depressive mood and a need for help, and $12 \%$ expressing depressive symptoms but expressing no need for professional intervention in their mood-related difficulties. Whether the latter group was already treated, thus making any further treatment option unnecessary or other reasons governed their decision to decline help, remains a matter of speculation.

In several cross-sectional studies, postal screening was used to determine the prevalence of depressive symptoms in diabetic patients, yielding different response rates. In a study carried out in both metropolitan and rural areas in Australia [16], a response rate of $47 \%$ was obtained, while a study of older Australian adults reached 29\% of the target sample [31]. A study by De Groot et al. [32] based in rural Appalachian counties gave a response rate of $46 \%$ (defined as answering to the letter of invitation), and an Irish study of patients with type 1 and type 2 diabetes had a response rate of $71 \%$ [33]. It could be speculated that the lower response rate obtained in our study was due to the fact that those who were not motivated to participate in the interventions were less likely to return the mailed questionnaire, despite the instructions asking to do so in any case.

Postal screening for depression by using the PHQ-2 has been shown to capture more positive screenings in medically ill older adults as compared with phone administration of the same questionnaire- $15.1 \%$ versus $6.5 \%$ [34]. The authors suggest that postal screening by a combination of the PHQ2 , self-reported antidepressant use, and reported diagnosis of depression can capture the greatest number of persons with possible depression. The proportion of patients with elevated depressive symptoms reached by our screening procedure was $18 \%$ of the total number of patients who had been sent the questionnaire $(n=4196)$. Since the previously determined prevalence of depressive symptoms in type 2 diabetic patients treated at our clinic was $22 \%$ [35], it could be hypothesized that not all depressed type 2 patients were reached by the postal screening procedure. Among the $18 \%$ of patients who were contacted by telephone for a more detailed depression assessment, some were shown to have other possible psychological difficulties, such as anxiety, or insomnia, rather than elevated depressive symptoms. Therefore, the true proportion of depressed individuals who were not reached by the screening was probably underestimated. 


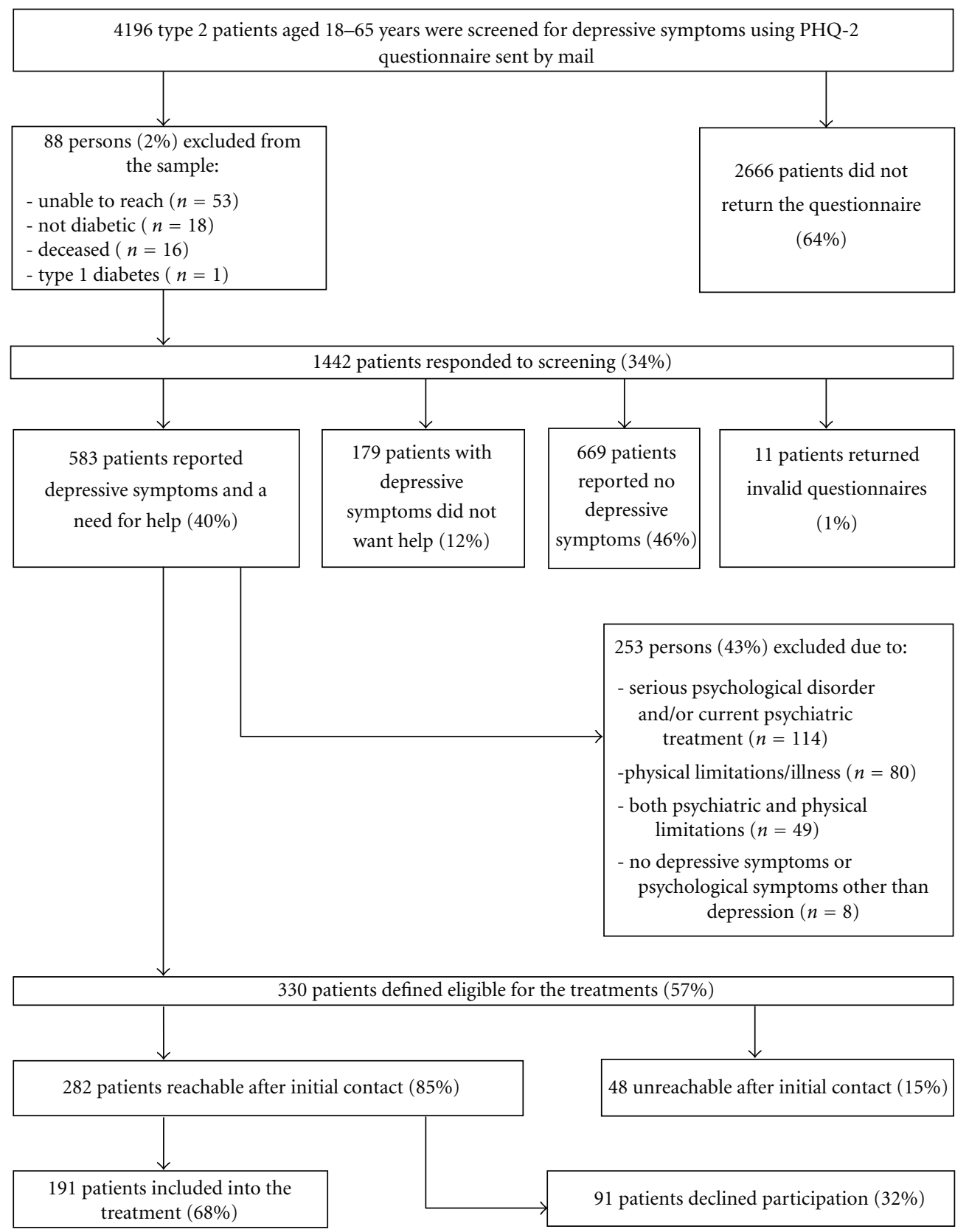

FIGURE 1: Flowchart of 4196 type 2 patients identified and recruited for trial participation.

Literature provides scarce evidence of demographic and clinical characteristics that may differentiate respondents and nonrespondents to depression screening. In this study, respondents were characterized by older age and relatively better indicators of diabetes management including glycaemic control and LDL and HDL cholesterol. Although these differences between the two groups could be interpreted in terms of statistical rather than clinical relevance, as shown by relatively small effect sizes, responsiveness to screening was independently predicted by diabetes-related indicators-BMI, HbA1C, HDL-and by age. In the studied cohort of type 2 diabetic patients, older individuals with better clinical status were more likely to return the questionnaire inquiring into their emotional state, regardless of whether they actually experienced depressive symptoms or not. Whether such self-selection may be analyzed in terms of differences in self-care and attitudes towards health-related issues remains to be clarified.

Of the respondents screened positively for depressive symptoms, 80 had been excluded from the interventions due to physical limitations or concomitant illnesses, 114 due to a previously diagnosed psychiatric disorder or current psychiatric treatment, 49 due to both psychiatric and physical limitations, and 8 due to no depressive symptoms detected by the structured clinical interview administered by phone or having psychological symptoms other than depression. 
TABLE 1: Demographic and clinical variables in patients who responded and did not respond to depression screening.

\begin{tabular}{|c|c|c|c|c|c|c|}
\hline & \multicolumn{4}{|c|}{ Univariate analyses } & \multirow{2}{*}{\multicolumn{2}{|c|}{$\begin{array}{c}\text { Multivariate model } \\
\text { Responders }=\text { reference }\end{array}$}} \\
\hline & \multirow{2}{*}{$\begin{array}{c}\text { Responders } \\
\text { Mean } \pm \text { SD (\%) }\end{array}$} & \multirow{2}{*}{$\begin{array}{l}\text { Nonresponders } \\
\text { Mean } \pm \text { SD (\%) }\end{array}$} & \multirow[b]{2}{*}{$P$} & \multirow[b]{2}{*}{ Cohen's $d$} & & \\
\hline & & & & & OR $(95 \% \mathrm{CI})$ & $P$ \\
\hline \multicolumn{7}{|l|}{ Gender } \\
\hline$($ female $=$ referent $)$ & $(44.8)$ & $(43.2)$ & .323 & N/A & $1.04(.90-1.21)$ & .608 \\
\hline Age & $58.2 \pm 5.92$ & $55.6 \pm 8.00$ & $<.001$ & .369 & $1.04(1.03-1.05)$ & $<.001$ \\
\hline BMI & $30.0 \pm 4.87$ & $29.9 \pm 4.71$ & .490 & .021 & $1.01(1.00-1.03)$ & .078 \\
\hline $\mathrm{HbA1C}$ & $7.1 \pm 1.32$ & $7.2 \pm 1.39$ & .025 & .074 & $.93(.88-.99)$ & .012 \\
\hline Total cholesterol & $5.15 \pm 1.153$ & $5.24 \pm 1.358$ & .038 & .071 & N/A & N/A \\
\hline LDL & $2.92 \pm .972$ & $3.00 \pm 1.050$ & .011 & .079 & $.92(.86-.99)$ & .034 \\
\hline $\mathrm{HDL}$ & $1.34 \pm .326$ & $1.32 \pm .323$ & .112 & .062 & $1.11(.88-1.41)$ & .380 \\
\hline Triglycerides & $2.20 \pm .067$ & $2.22 \pm 1.803$ & .806 & .016 & $1.03(.99-1.07)$ & .224 \\
\hline
\end{tabular}

TABLE 2: Demographic and clinical variables in patients who accepted treatment and those who did not.

\begin{tabular}{|c|c|c|c|c|c|c|}
\hline & \multicolumn{4}{|c|}{ Descriptives } & \multirow{2}{*}{\multicolumn{2}{|c|}{$\begin{array}{c}\text { Multivariate } \\
\text { Participating }=\text { reference }\end{array}$}} \\
\hline & \multirow{2}{*}{$\begin{array}{c}\text { Participating }(n=191) \\
\text { Mean } \pm \text { SD }(\%)\end{array}$} & \multirow{2}{*}{$\begin{array}{c}\text { Not participating }(n=91) \\
\text { Mean } \pm \operatorname{SD}(\%)\end{array}$} & \multirow[b]{2}{*}{$P$} & \multirow[b]{2}{*}{ Cohen's $d$} & & \\
\hline & & & & & OR $(95 \%$ CI $)$ & $P$ \\
\hline \multicolumn{7}{|l|}{ Gender } \\
\hline (female = reference $)$ & $(55)$ & (39) & .074 & N/A & $1.592(.833-3.041)$ & .159 \\
\hline Age (years) & $58.4 \pm 5.41$ & $57.7 \pm 6.15$ & .310 & .121 & $.979(.923-1.039)$ & .482 \\
\hline Education (years) & $12.4 \pm 2.45$ & $12.0 \pm 2.49$ & .272 & .162 & $1.205(1.053-1.379)$ & .007 \\
\hline \multicolumn{7}{|l|}{ Professional status } \\
\hline (active = reference $)$ & $(30.4)$ & $(44.9)$ & .022 & N/A & $3.241(1.530-6.865)$ & .002 \\
\hline \multicolumn{7}{|l|}{ Socioeconomic status } \\
\hline (good = reference) & $(43.3)$ & $(36.2)$ & & & & \\
\hline Average & $(44.9)$ & $(47.3)$ & .399 & N/A & $.864(.450-1.658)$ & .660 \\
\hline Poor & $(11.8)$ & $(16.5)$ & & & $.787(.311-1.991)$ & .613 \\
\hline \multicolumn{7}{|l|}{ Family status } \\
\hline$($ married $=$ reference $)$ & $(74.6)$ & $(78.0)$ & .556 & N/A & $.812(.399-1.654)$ & .567 \\
\hline Acute stress & $(42.6)$ & $(39.5)$ & .684 & N/A & N/A & \\
\hline \multicolumn{7}{|l|}{ Chronic stress } \\
\hline (yes = reference $)$ & $(58.2)$ & $(60.0)$ & .880 & N/A & N/A & \\
\hline BMI $\left(\mathrm{kg} / \mathrm{m}^{2}\right)$ & $29.7 \pm 4.29$ & $31.03 \pm 4.86$ & .024 & .290 & $.910(.850-.975)$ & .007 \\
\hline $\operatorname{HbA1C}(\%)$ & $7.1 \pm 1.30$ & $7.0 \pm 1.28$ & .437 & .078 & $1.246(.972-1.597)$ & .082 \\
\hline Total cholesterol (mmol/L) & $5.20 \pm 1.116$ & $5.08 \pm 1.006$ & .417 & .113 & N/A & \\
\hline LDL cholesterol (mmol/L) & $2.97 \pm .994$ & $2.87 \pm .852$ & .458 & .108 & $1.112(.803-1.539)$ & .522 \\
\hline HDL cholesterol (mmol/L) & $1.40 \pm .300$ & $1.34 \pm .339$ & .108 & .187 & $.549(.183-1.645)$ & .284 \\
\hline Triglycerides $(\mathrm{mmol} / \mathrm{L})$ & $1.87 \pm .965$ & $2.44 \pm 2.997$ & .023 & .256 & $.838(.692-1.016)$ & .072 \\
\hline
\end{tabular}

These individuals were provided with information about treatment options or advised to start individual psychological and/or psychiatric treatment at our diabetes clinic.

About two-thirds of the eligible respondents $(68 \%)$ were included into the structured treatments for subclinical depression-psychoeducation based on cognitive-behavioral principles, physical exercise, or diabetes reeducation. The remaining 91 declined participation, most frequently reporting competing priorities, such as professional and family obligations or lack of time as reasons for nonparticipation.
The reach of behavioral interventions is increasingly considered important in determining the real impact of efforts to support patient well-being and diabetes self-care. Within the RE-AIM framework [36], reach is defined as the percentage of potential participants who are exposed to an intervention, and to their representativeness. The reach of $68 \%$ of eligible patients obtained in our study can be considered high, taking into account that it was achieved within the context of recruitment for an RCT, in which participants must be willing to take part in any of the treatment options to which 
they could be randomized. In comparison, the reach of a web-based cognitive behavioral therapy program to reduce symptoms of depression and diabetes-related distress [37] has been shown to be $47 \%$ of all interested patients.

A study by Glasgow et al. [38] demonstrated that giving eligible patients a chance to choose the treatment condition increased the participation rate in comparison with a randomized consent condition (48\% versus $37 \%$ ).

Besides reach, representativeness of participating patients is considered relevant for translating RCT findings into regular clinical practice. In a study of internet-based weight loss programs [39] with a 30\% participation rate, individuals with higher income, better education, and health literacy proficiency have been shown to be significantly more likely to participate. In a study by Toobert et al. [40], although the sample recruited for a lifestyle intervention in Latinas with diabetes was highly representative, participants and nonparticipants differed in the type of diabetes treatment. The observation that randomized patients may differ from those who were not randomized for intervention due to their unwillingness to participate has been confirmed in patients with irritable bowel syndrome as well [41], as patients with a higher intensity of abdominal pain and a longer disease history were shown to be more likely to participate in the intervention. In our study professionally inactive/retired, better educated, and less overweight persons were more likely to agree to participate in treatments for subsyndromal depression. On the other hand, the patients willing to participate did not differ from those refusing participation with respect to some demographic and psychological variables in which differences would be expected-such as the experience of acute or chronic stress. An assumption can be made that experience of stressful events is not necessarily associated with patients' needs to receive help but can act as both a motivator or an inhibitor of seeking help.

The obtained results allow a speculation that personal and disease-related indicators, but also specific life circumstances — such as being professionally inactive at the age in which active professional roles are expected-might contribute to patients' decision to accept the treatment. The effects of professional status may not be fully attributable to the issues of available time (since the interventions themselves offered flexibility in that regard) but also to the patients' psychological needs and attitudes towards health. Although differences between the two groups were small, their statistical significance justifies taking them into consideration in elaborating the applicability of final study results. An assumption can be made that devising interventions that would be better adjusted for professionally active patients, persons with a lower educational level, and those with higher body weight may be appropriate.

Another hypothetical way to increase patient participation in psychological treatments might be associated with a degree to which psychological issues are addressed in diabetes care in general. The more psychological topics are recognized and discussed within regular diabetes care, the greater readiness on patients' side to engage into treatments can be expected.
The presented data have some advantages and limitations. The main strength of this study is that it was carried out in a large cohort of type 2 diabetic patients. This allows a relatively broad generalizability of the findings on the characteristics associated with patients' willingness to respond to depression screening. However, the differences between persons who did and did not choose to participate in the treatment programs are small in magnitude and may be significantly influenced by the specifics of the design of the randomized clinical trial or of the studied subpopulation of diabetic persons. Therefore, further studies are needed to establish whether personal and disease-related characteristics predict the likelihood of participating in behavioral treatment for mood difficulties across different contexts and populations.

\section{Conclusion}

The processes of screening for depressive symptoms and recruiting type 2 diabetes patients for treatment of subsyndromal depression seem to be characterized by differences in demographic and clinical features of patients who were reached versus those who were not. The findings may be taken into consideration while evaluating the generalizability of trial results.

\section{Acknowledgment}

The data presented in this paper were a part of a study supported by a New Horizons grant of the European Foundation for the Study of Diabetes (EFSD).

\section{References}

[1] M. T. Schram, C. A. Baan, and F. Pouwer, "Depression and quality of life in patients with diabetes: a systematic review from the European Depression in Diabetes (EDID) research consortium," Current Diabetes Reviews, vol. 5, no. 2, pp. 112119, 2009.

[2] J. S. Gonzalez, M. Peyrot, L. A. McCarl et al., "Depression and diabetes treatment nonadherence: a meta-analysis," Diabetes Care, vol. 31, no. 12, pp. 2398-2403, 2008.

[3] P. J. Lustman, R. J. Anderson, K. E. Freedland, M. De Groot, R. M. Carney, and R. E. Clouse, "Depression and poor glycemic control: a meta-analytic review of the literature," Diabetes Care, vol. 23, no. 7, pp. 934-942, 2000.

[4] M. De Groot, R. Anderson, K. E. Freedland, R. E. Clouse, and P. J. Lustman, "Association of depression and diabetes complications: a meta-analysis," Psychosomatic Medicine, vol. 63, no. 4, pp. 619-630, 2001.

[5] L. E. Egede, "Effect of depression on self-management behaviors and health outcomes in adults with type 2 diabetes," Current Diabetes Reviews, vol. 1, no. 3, pp. 235-243, 2005.

[6] K. Ismail, K. Winkley, D. Stahl, T. Chalder, and M. Edmonds, "A cohort study of people with diabetes and their first foot ulcer: the role of depression on mortality," Diabetes Care, vol. 30, no. 6, pp. 1473-1479, 2007.

[7] F. Pouwer, A. T. F. Beekman, C. Lubach, and F. J. Snoek, "Nurses' recognition and registration of depression, anxiety and diabetes-specific emotional problems in outpatients with 
diabetes mellitus," Patient Education and Counseling, vol. 60, no. 2, pp. 235-240, 2006.

[8] C. M. van der Feltz-Cornelis, J. A. C. Meeuwissen, F. J. De Jong, R. Hoedeman, and I. Elfeddali, "Randomised controlled trial of a psychiatric consultation model for treatment of common mental disorder in the occupational health setting," $B M C$ Health Services Research, vol. 7, article 29, 2007.

[9] American Diabetes Association, "Standards of medical care in diabetes_2009," Diabetes Care, vol. 32, supplement 1, pp. S13-S61, 2009.

[10] IDF Clinical Guidelines Task Force, Global Guideline for Type 2 Diabetes, International Diabetes Federation, Brussels, Belgium, 2005.

[11] National Institute for Health and Clinical Excellence, "Depression: management of depression in primary care and secondary care," National Institute for Health and Clinical Excellence, 2009, http://publications.nice.org.uk/depressionin-adults-cg90.

[12] N. Hermanns, B. Kulzer, M. Krichbaum, T. Kubiak, and T. Haak, "How to screen for depression and emotional problems in patients with diabetes: comparison of screening characteristics of depression questionnaires, measurement of diabetes-specific emotional problems and standard clinical assessment," Diabetologia, vol. 49, no. 3, pp. 469-477, 2006.

[13] K. M. Van Steenbergen-Weijenburg, L. De Vroege, R. R. Ploeger et al., "Validation of the PHQ-9 as a screening instrument for depression in diabetes patients in specialized outpatient clinics," BMC Health Services Research, vol. 10, article 235, 2010.

[14] K. Kroenke, R. L. Spitzer, and J. B. W. Williams, "The patient health questionnaire-2: Validity of a two-item depression screener," Medical Care, vol. 41, no. 11, pp. 1284-1292, 2003.

[15] M. McHale, J. Hendrikz, F. Dann, and J. Kenardy, "Screening for depression in patients with diabetes mellitus," Psychosomatic Medicine, vol. 70, no. 8, pp. 869-874, 2008.

[16] P. Reddy, D. Ford, and J. A. Dunbar, "Improving the quality of diabetes care in general practice," Australian Journal of Rural Health, vol. 18, no. 5, pp. 187-193, 2010.

[17] A. J. Mitchell and J. C. Coyne, Screening for Depression in Clinical Practice: An Evidence-Based Guide, Oxford University Press, Oxford, UK, 2010.

[18] S. Gilbody, T. Sheldon, and A. House, "Screening and casefinding instruments for depression: a meta-analysis," Canadian Medical Association Journal, vol. 178, no. 8, pp. 997-1003, 2008.

[19] F. Pouwer, C. J. Tack, P. H. L. M. Geelhoed-Duijvestijn et al., "Limited effect of screening for depression with written feedback in outpatients with diabetes mellitus: a randomised controlled trial," Diabetologia, vol. 54, no. 4, pp. 741-748, 2011.

[20] B. D. Thombs, P. De Jonge, J. C. Coyne et al., "Depression screening and patient outcomes in cardiovascular care: a systematic review," Journal of the American Medical Association, vol. 300, no. 18, pp. 2161-2171, 2008.

[21] F. Pouwer, F. J. Snoek, H. M. van der Ploeg, H. J. Adèr, and R. J. Heine, "Monitoring of psychological well-being in outpatients with diabetes: effects on mood, $\operatorname{HbA}(1 \mathrm{c})$, and the patient's evaluation of the quality of diabetes care: a randomized controlled trial," Diabetes Care, vol. 24, no. 11, pp. 1929-1935, 2001

[22] F. J. Snoek, N. Y. A. Kersch, E. Eldrup et al., "Monitoring of Individual Needs in Diabetes (MIND)-2: follow-up data from the Cross-National Diabetes Attitudes, Wishes, and Needs (DAWN) MIND Study," Diabetes Care. In press.
[23] W. J. Katon, M. Von Korff, E. H. B. Lin et al., "The pathways study: a randomized trial of collaborative care in patients with diabetes and depression," Archives of General Psychiatry, vol. 61, no. 10, pp. 1042-1049, 2004.

[24] W. J. Katon, E. H. B. Lin, M. V. Korff et al., "Collaborative care for patients with depression and chronic illnesses," New England Journal of Medicine, vol. 363, no. 27, pp. 2611-2620, 2010.

[25] T. Poljičanin, I. Pavlić-Renar, and Z. Metelko, "Crodiab netelectronic diabetes registry," Acta Medica Croatica, vol. 59, no. 3, pp. 185-189, 2005.

[26] "Cognitive behavioral therapy in elderly type 2 diabetes patients with minor depression or mild major depression: a randomized controlled trial," Current Controlled Trials, c/o BioMed Central, Identifier ISRCTN58007098, ISRCTN, London, UK, 2009 May, http://www.controlled-trials.com/ ISRCTN58007098/petrak.

[27] M. Pibernik-Okanović, D. Ajduković, M. V. Lovrenčić, and N. Hermanns, "Does treatment of subsyndromal depression improve depression and diabetes related outcomes: protocol for a randomised controlled comparison of psycho-education, physical exercise and treatment as usual," Trials, vol. 12, article $17,2011$.

[28] M. A. Whooley, A. L. Avins, J. Miranda, and W. S. Browner, "Case-finding instruments for depression: two questions are as good as many," Journal of General Internal Medicine, vol. 12, no. 7, pp. 439-445, 1997.

[29] N. Kerse, K. Falloon, S. A. Moyes et al., "DeLLITE Depression in late life: an intervention trial of exercise. Design and recruitment of a randomised controlled trial," BMC Geriatrics, vol. 8, article 12, 2008.

[30] B. Arroll, F. Goodyear-Smith, N. Kerse, T. Fishman, and J. Gunn, "Effect of the addition of a "help" question to two screening questions on specificity for diagnosis of depression in general practice: diagnostic validity study," British Medical Journal, vol. 331, no. 7521, pp. 884-886, 2005.

[31] J. Pirkis, J. Pfaff, M. Williamson et al., "The community prevalence of depression in older Australians," Journal of Affective Disorders, vol. 115, no. 1-2, pp. 54-61, 2009.

[32] M. De Groot, T. Doyle, E. Hockman et al., "Depression among type 2 diabetes rural Appalachian clinic attendees," Diabetes Care, vol. 30, no. 6, pp. 1602-1604, 2007.

[33] M. M. Collins, P. Corcoran, and I. J. Perry, "Anxiety and depression symptoms in patients with diabetes," Diabetic Medicine, vol. 26, no. 2, pp. 153-161, 2009.

[34] J. K. Taylor, M. Schoenbaum, W. J. Katon, H. A. Pincus, D. M. Hogan, and J. Unützer, "Strategies for identifying and channeling patients for depression care management," American Journal of Managed Care, vol. 14, no. 8, pp. 497-504, 2008.

[35] M. Pibernik-Okanovic, K. Peros, S. Szabo, D. Begic, and Z. Metelko, "Depression in Croatian type 2 diabetic patients: Prevalence and risk factors. A Croatian survey from the European Depression in Diabetes (EDID) Research Consortium," Diabetic Medicine, vol. 22, no. 7, pp. 942-945, 2005.

[36] R. E. Glasgow, T. M. Vogt, and S. M. Boles, "Evaluating the public health impact of health promotion interventions: the RE-AIM framework," American Journal of Public Health, vol. 89, no. 9, pp. 1322-1327, 1999.

[37] K. Van Bastelaar, P. Cuijpers, F. Pouwer, H. Riper, and F. J. Snoek, "Development and reach of a web-based cognitive behavioural therapy programme to reduce symptoms of depression and diabetes-specific distress," Patient Education and Counseling, vol. 84, no. 1, pp. 49-55, 2011. 
[38] R. E. Glasgow, L. L. Edwards, H. Whitesides, N. Carroll, T. J. Sanders, and B. L. McCray, "Reach and effectiveness of DVD and in-person diabetes self-management education," Chronic Illness, vol. 5, no. 4, pp. 243-249, 2009.

[39] W. You, F. A. Almeida, J. M. Zoellner et al., "Who participates in internet-based worksite weight loss programs?" BMC Public Health, vol. 11, article 709, 2011.

[40] D. J. Toobert, L. A. Strycker, R. E. Glasgow et al., "Viva bien!: overcoming recruitment challenges in a multiple-risk-factor diabetes trial," American Journal of Health Behavior, vol. 34, no. 4, pp. 432-441, 2010.

[41] C. J. Bijkerk, J. W. M. Muris, J. A. Knottnerus, A. W. Hoes, and N. J. de Wit, "Randomized patients in IBS research had different disease characteristics compared to eligible and recruited patients," Journal of Clinical Epidemiology, vol. 61, no. 11, pp. 1176-1181, 2008. 


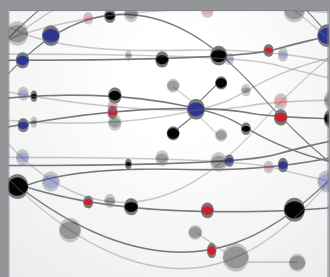

The Scientific World Journal
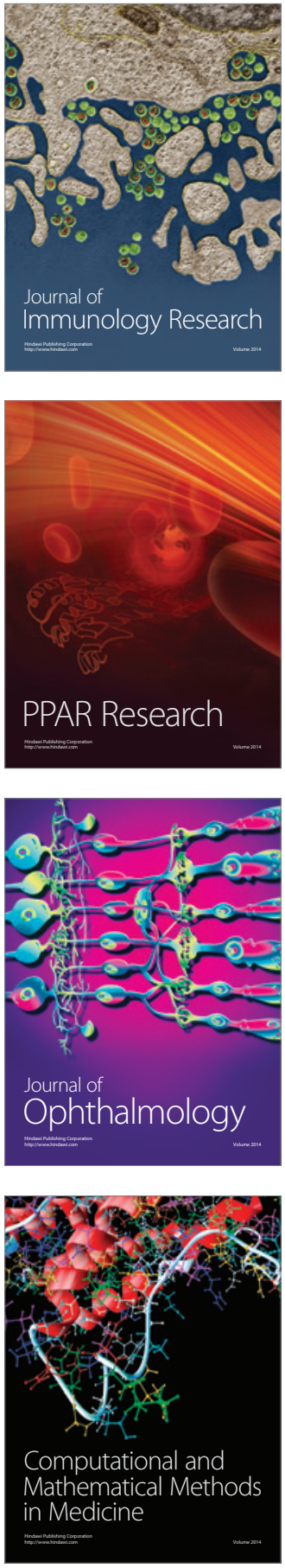

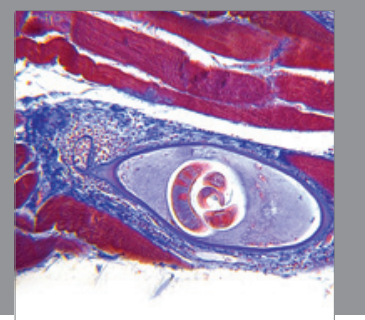

Gastroenterology

Research and Practice
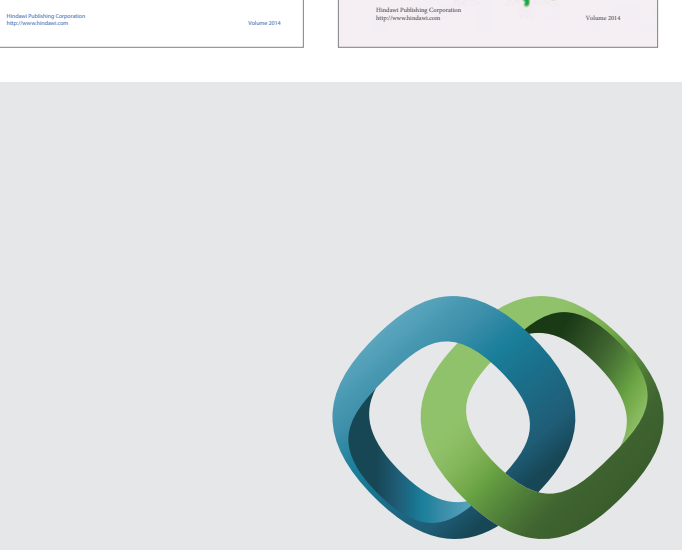

\section{Hindawi}

Submit your manuscripts at

http://www.hindawi.com
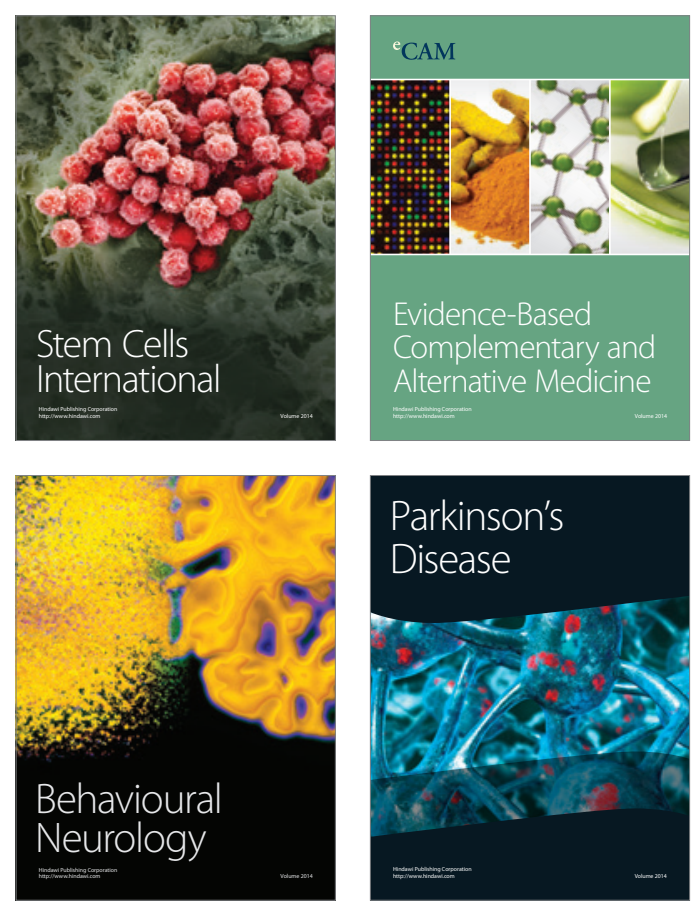

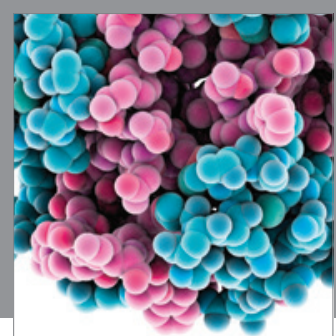

Journal of
Diabetes Research

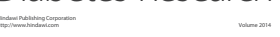

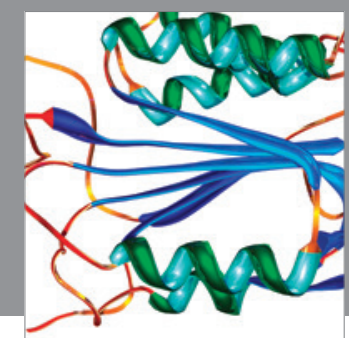

Disease Markers
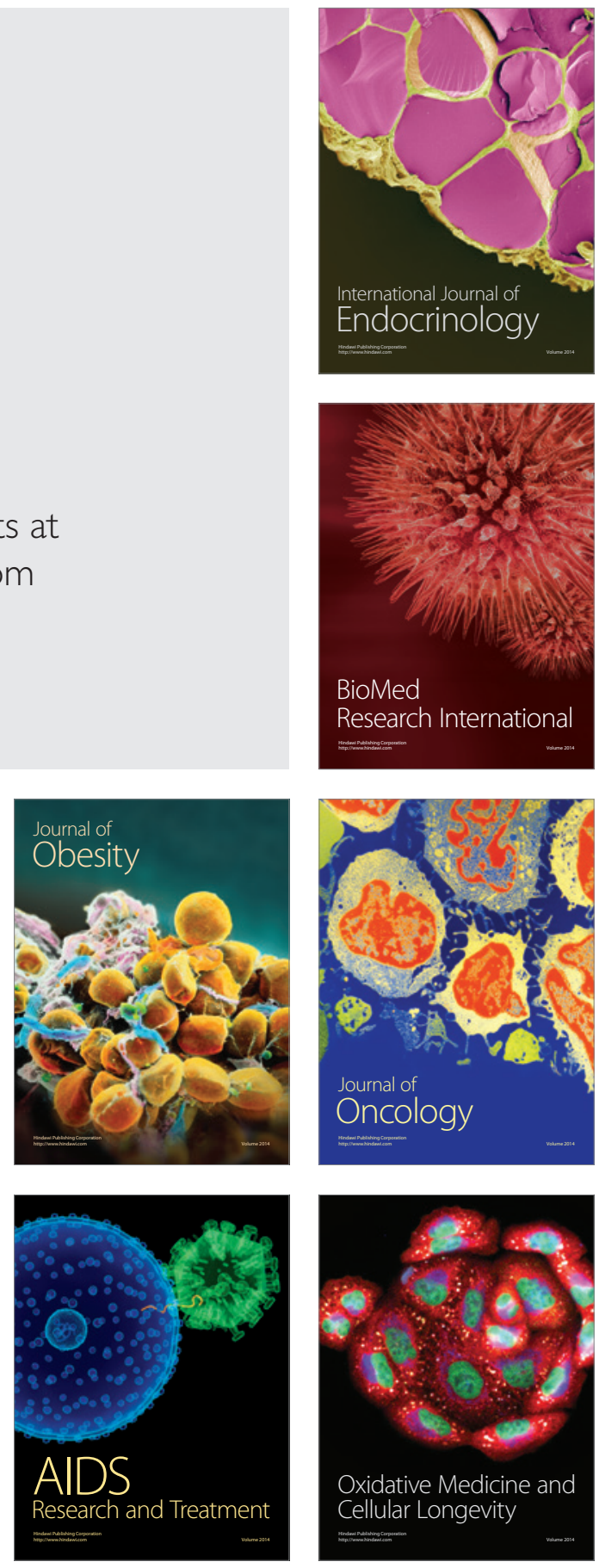